\title{
RANCANGAN PERPUSTAKAAN DIGITAL BERBASIS WEB FAKULTAS SAINS DAN TEKNOLOGI UIN IMAM BONJOL PADANG DENGAN MENGGUNAKAN OMEKA
}

\author{
Mega Orina Fitri \\ Prodi DIII Ilmu Perpustakaan Fakultas Adab dan Humaniora \\ Universitas Islam Negeri (UIN) Imam Bonjol Padang \\ Email: mofana76@gmail.com
}

\begin{abstract}
Abstrak: Penelitian ini dilatarbelakangi oleh belum adanya perpustakaan yang dapat diakses oleh dosen dan mahasiswa Fakultas Sains dan Teknologi Universitas Islam Negeri (UIN) Imam Bonjol Padang. Hal ini disebabkan karena fakultas ini baru beberapa bulan berdiri, yaitu Januari 2020 sehingga fasilitas dan anggaran yang tersedia masih minim. Pembangunan perpustakaan dan penyediaan buku tercetak tentunya akan membutuhkan tempat, waktu yang cukup lama dan biaya yang besar. Sedangkan sebenarnya buku tersebut dapat diakses dalam bentuk format pdf dari berbagai link. Penelitian ini bertujuan untuk merancang perpustakaan digital Fakultas Sains dan Teknologi, sehingga dapat segera dimanfaatkan oleh sivitas akademika yang memerlukannya. Perpustakaan digital dibangun menggunakan Omeka, suatu aplikasi repository institusional berbasis web dan dapat diperoleh secara gratis. Hasil akhir dari penelitian ini adalah terbentuknya rancangan Perpustakaan Digital Fakultas Sains dan Teknologi UIN Imam Bonjol Padang, yang sudah terisi sampel koleksi.
\end{abstract}

Kata kunci: Aplikasi, Digital, Perpustakaan, Omeka, Repository

\section{PENDAHULUAN}

$\mathrm{F}$ akultas Sains dan Teknologi merupakan fakultas terbaru yang dimiliki oleh Universitas Imam Bonjol (UIN) Padang. Saat ini fakultas tersebut baru memperoleh ijin Kemenag untuk memiliki 2 program studi, dari 5 program studi yang diusulkan oleh UIN Imam Bonjol Padang. Kedua program studi tersebut adalah program studi Sistem Informasi dan program studi Matematika. Sebagai fakultas yang baru berdiri, tentunya banyak sekali kebutuhan yang harus disediakan untuk kelancaran perkuliahan. Salah satunya adalah kebutuhan akan perpustakaan, yang berfungsi untuk memenuhi kebutuhan informasi sivitas akademika terutama yang berada di lingkungan fakultas tersebut.

Sebagaimana banyak disebutkan, perpustakaan adalah jantung dari perguruan tinggi, yang dapat "memompakan" informasi kepada sivitas akademika. Perpustakaan juga merupakan unsur penting karena menjadi sumber informasi yang dapat menunjang Tri Dharma Perguruan Tinggi.

Perkembangan teknologi informasi menyebabkan koleksi perpustakaan saat ini sudah banyak beralih dari media konvensional ke media digital. Walaupun demikian, 
media konvensional masih tetap dibutuhkan karena tidak semua orang menyukai membaca melalui media digital. Mata menjadi lebih cepat lelah dan rusak jika membaca melalui gadget dibandingkan membaca media cetak. Selain itu tidak semua koleksi yang diijinkan oleh penulis dan penerbitnya untuk disimpan dalam bentuk digital karena berhubungan dengan hak cipta.

Tetapi penyediaan koleksi perpustakaan dalam bentuk media konvensional tentunya memerlukan tempat penyimpanan yang luas, dan biaya yang besar untuk membeli dan menyediakan koleksi tersebut. Hal ini belum dapat dilakukan oleh Fakultas Sains dan Teknologi UIN Imam Bonjol Padang, mengingat usianya yang baru beberapa bulan, dan saat ini anggarannya masih menumpang ke Fakultas Ekonomi dan Bisnis Islam (FEBI) UIN Imam Bonjol Padang. Karena itu, penyediaan tempat dan koleksi untuk perpustakaan konvensional belum mungkin dilakukan oleh Fakultas Sains dan Teknologi.

Sementara itu kebutuhan akan perpustakaan sangat mendesak karena Tri Dharma Perguruan Tinggi harus terus berjalan. Ditambah lagi sekarang sudah banyak koleksi perpustakaan yang tersedia dalam bentuk file digital seperti pdf dan dibagikan secara gratis. Hanya saja koleksi-koleksi tersebut belum tersimpan dalam suatu tempat yang mudah diakses oleh sivitas akademika Fakultas Sains dan Teknologi UIN Imam Bonjol Padang.

Agar koleksi tersebut terkumpul dalam suatu tempat yang mudah diakses sehingga kebutuhan informasi sivitas akademika terpenuhi walaupun belum maksimal, maka perlu dibangun sebuah repository. Repository tersebut berbentuk Perpustakaan Digital Fakultas Sains dan Teknologi UIN Imam Bonjol Padang, yang berbasis web. Perangkat lunak yang digunakan adalah Omeka 2.7.

Rumusan masalah pada penelitian ini adalah bagaimana bentuk rancangan perpustakaan digital berbasis web milik Fakultas Sains dan Teknologi UIN Imam Bonjol Padang dengan menggunakan Omeka tersebut? Adapun tujuan dari penelitian ini adalah dihasilkannya rancangan perpustakaan digital berbasis web sehingga dapat diakses oleh sivitas akademika UIN Imam Bonjol Padang pada umumnya, dan sivitas akademika Fakultas Sains dan Teknologi pada khususnya.

\section{METODE PENELITIAN}

\section{A. Jenis dan Lokasi Penelitian}

Dalam penelitian ini penulis menggunakan jenis penelitian kualitatif yang bersifat pengembangan produk yang digunakan dalam bidang pendidikan. Sedangkan lokasi penelitian adalah di Fakultas Sains dan Teknologi UIN Imam Bonjol Padang. Fakultas tersebut berlokasi di kampus 3 UIN Imam Bonjol Padang, Sungai Bangek.

\section{B. Teknik dan Instrumen Pengumpulan Data}

Penelitian ini menggunakan teknik pengumpulan data observasi langsung ke lapangan dan kuisioner. Sedangkan instrumen yang digunakan adalah panduan observasi berupa chek list dan lembaran daftar pertanyaan kuisioner. 


\section{Jenis Data}

\section{Data Primer}

Data primer diperoleh langsung dari hasil observasi ke Fakultas Sains dan Teknologi yang berlokasi di kampus 3 UIN Imam Bonjol Padang, Sungai Bangek. Selanjutnya dilakukan pengunduhan instaler Omeka versi 2.7 dari website resmi Omeka www.omeka.org .

\section{Data Sekunder}

Data sekunder pada penelitian ini berasal dari berbagai referensi seperti artikel,arsip, jurnal dan sumber bacaan lain yang berhubungan dengan masalah yang dibahas. Data sekunder digunakan sebagai kutipan, tambahan pengetahuan dan menjadi referensi dalam penelitian pengembangan ini.

\section{KONSEP DAN PERANCANGAN}

\section{A. Repository dan Perpustakaan Digital}

Istilah repository sudah tidak asing lagi di dalam duniA perpustakaan. Secara sederhana, repository secara sederhana dapat diartikan sebagai tempat penyimpanan. Perpustakaan, yang digunakan untuk menyimpan atau merekam koleksi bahan pustaka adalah contoh repository dalam arti luas. Di era digital ini, koleksi perpustakaan banyak beralih menjadi koleksi digital. Saat ini repository lebih mengacu pada tempat penyimpanan koleksi digital, termasuk di dalamnya adalah koleksi tercetak yang telah dialihmediakan menjadi koleksi digital. (Faida,2015). Jika tempat penyimpanan itu dimiliki oleh suatu organisasi atau institusi, maka repository itu disebut sebagai institutional repository.

Karena adanya koleksi tercetak dan digital, maka terdapat tiga bentuk perpustakaan, yaitu perpustakaan konvensional, perpustakaan digital, dan perpustakaan hybrid. Perpustakaan konvensional adalah perpustakaan yang memerlukan suatu ruangan dan rak untuk tempat pemyimpanan koleksi tercetak dan lainnya. Sedangkan perpustakaan digital menurut Wikipedia, adalah perpustakaan yang mempunyai koleksi dalam bentuk format digital dan dapat diakses dengan komputer. Berbeda dengan perpustakaan konvensional, isi dari perpustakaan digital berada dalam suatu komputer server yang dapat ditempatkan secara lokal, maupun di lokasi yang jauh, namun dapat diakses dengan cepat dan mudah lewat jaringan komputer. Perpustakaan digital (digital library) dikenal juga sebagai electronic library (e-library) atau virtual library. (Wikipedia,2020). Kombinasi perpustakaan konvensional dan digital disebut sebagai perpustakaan hybrid, dimana sebagian koleksi ada yang tercetak dan sebagian lagi berupa koleksi digital.

Perkembangan teknologi menyebabkan semakin menjamurnya perpustakaan digital. Tidak hanya dapat diakses melalui website (berbasis web), tetapi sekarang sudah banyak terdapat aplikasi perpustakaan digital yang melayani peminjaman buku yang dapat diunduh melalui smartphone dengan sistem operasi Android. Misalkan aplikasi iPusnas, ePerpus, T-Perpus, Handy Library, Anybooks dan Wattpad.(Fauziah,2019) Tetapi masih banyak juga institusi atau organisasi yang mengandalkan perpustakaan digital yang berbasis web. Terdapat bermacam perangkat lunak yang dapat digunakan untuk membangun perpustakaan digital berbasis web dan bersifat open source. Perangkat lunak yang populer digunakan sekarang adalah DSpace, ePrints dan Omeka. 


\section{B. Omeka}

Omeka adalah suatu Content Management System (CMS) yang digunakan sebagai repository online untuk koleksi digital. Omeka merupakan aplikasi berbasis web yang bersifat open source. Omeka memungkinkan penggunanya untuk mempublikasikan koleksi yang dimilikinya dengan berbagai fitur tambahan karena memiliki plugin dan tersedia dalam berbagai tampilan atau desain.

Omeka dikembangkan oleh Roy Rosenzweig Center for History and New Media dari George Mason University. Omeka diluncurkan pertama kali pada tanggal 21 Februari 2008. Peresmian versi 1.0 adalah pada tanggal 2 Juni 2009. Omeka menggunakan standar internasional seperti Dublin Core Schema untuk metadata. Omeka memungkinkan para penggunanya untuk membuat web pages untuk koleksi digital.

Pengembangan Omeka dilakukan dengan menggunakan konsep web 2.0, yaitu pengelolaan web yang menyediakan bermacam fasilitas untuk pengguna seperti geolocation, tagging, social bookmarking, halaman partispasi pengguna, dll. Hal ini memungkinkan pengguna untuk memberikan masukan dan penilaian terhadap berbagai informasi yang dipublikasikan melalui web perpustakaan (Hakim,2015).

Dalam hal instalasi, Omeka memerlukan berbagai macam perangkat lunak, yaitu sistem operasi, bahasa pemrograman, dan Data Base Management System (DBMS), dan library. Sistem operasi yang direkomendasikan oleh Omeka adalah Linux. Tetapi Omeka tetap akan dapat berjalan dengan baik pada sistem operasi Windows. Untuk bahasa pemprograman, Omeka menggunakan Apache PHP. DBMS atau sistem pengelola basis data, digunakan MySQL. Dengan menggunakan perangkat lunak XAMPP, maka kebutuhan akan Apache PHP dan MySQL akan terpenuhi. Tampilan MySQL yang digunakan tersebut muncul dalam bentuk PhpMyAdmin. Sedangkan untuk library, yaitu file atau kumpulan file yang di dalamnya terdapat fungsi/kelas yang dibutuhkan aplikasi, Omeka menggunakan ImageMagick. ImageMagick adalah default Library yang digunakan untuk meng-generate thumbnails.

Sebagai suatu perangkat lunak, Omeka tentunya memiliki kelebihan dan kekurangan. Adapun kelebihan Omeka, seperti yang tertera di website resminya yaitu www.omeka.org, adalah :

1. Publikasi resmi koleksi perpustakaan pribadi atau instansi yang berbasis web.

2. Mudah digunakan dan hanya membutuhkan waktu setikar 5 menit untuk melakukan instalasi dan setup Omeka.

1. Biaya pengembangan yang diperlukan rendah karena instaler Omeka dapat diunduh secara gratis.

2. Fleksibel dan dapat dikembangkan lebih lanjut karena bersifat open source.

Selan itu, kelebihan Omeka adalah terdapatnya fitur : input metadata, import data, dan pertkaran data, serta tampilan yang cukup user friendly dan memungkinkan interaksi pengunjung online dengan konsep web 2.0 yang ditunjang oleh sistem kemanan yang baik. Sedangkan kekurangan dari Omeka adalah kurangnya dukungan support yang berbahasa Indonesia dan kurang bervariasinya desain theme (Nurrika,2012). Sebagai tambahan, jika dibandingkan dengan DSpace dan Eprints, maka kapasitas penyimpanan Omeka jauh lebih kecil. 


\section{HASIL DAN PEMBAHASAN}

Pada rancangan ini, Perpustakaan Digital Fakultas Sains dan Teknologi UIN Imam Bonjol Padang dinamakan e-Library Sainstek. Untuk merancang e-Library Sainstek ini, pertama kali diunduh, instalasi dan aktivasi XAMPP. Aktivasi XAMPP dilakukan dengan menekan tombol Start pada Apache dan MySQL pada XAMPP Control Panel. Hal ini dapat dilihat pada Gambar 1 berikut.

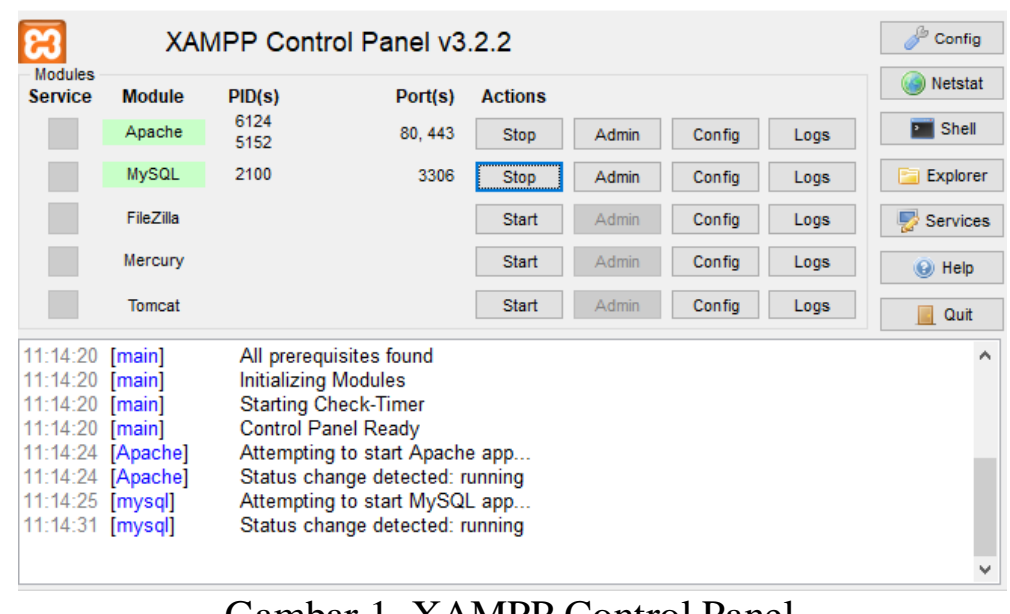

Gambar 1. XAMPP Control Panel

Selanjutnya Omeka Classic 2.7 yang berbentuk zip file diunduh dari website resmi Omeka, yaitu www.omeka.org. Zip file tersebut dipindahkan ke folder htdocs yang ada di folder XAMPP yang sudah terisntal di root direktori, dan dilakukan ekstraksi file tersebut dengan klik kanan dan memilih extract here. Setelah itu akan mumcul folder Omeka 2.7, yang kemudian diubah namanya menjadi Omeka. Basis data baru dengan nama Omeka dibuat di localhost/phpmyadmin. Lalu pada tab baru di browser diketik localhost/omeka, dan muncul tampilan seperti Gambar 2 berikut.

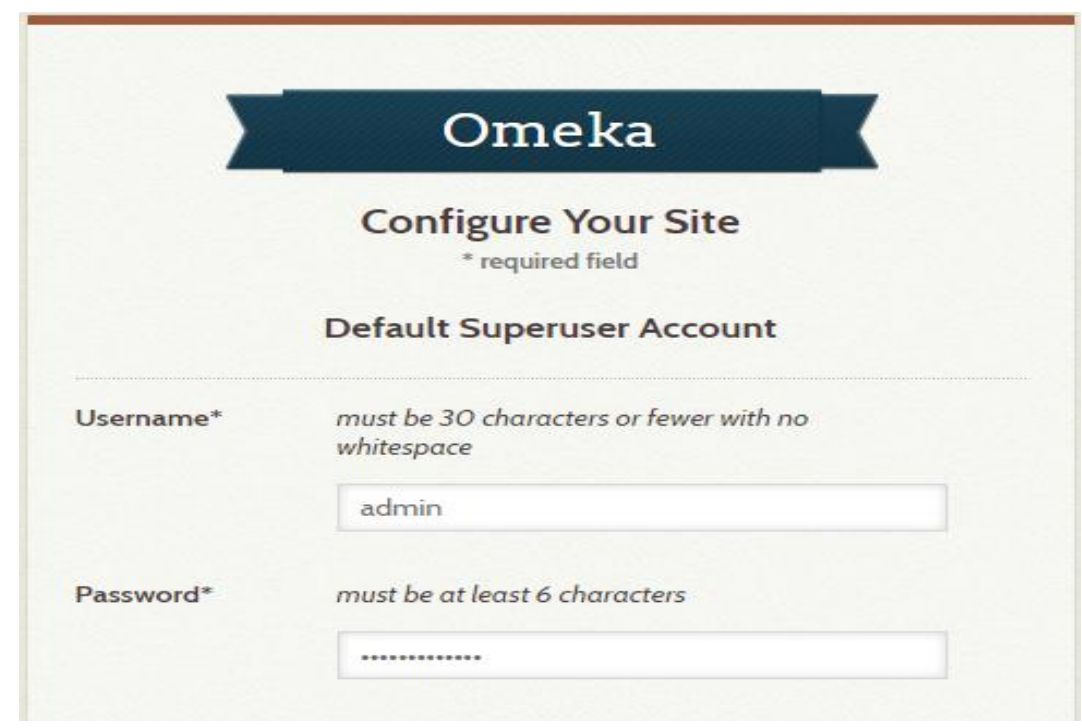

Gambar 2. Tahap Awal Instalasi Omeka 
Lakukan tahapan instalasi seperti yang diminta. Setelah sampai, pada tahap akhir instalasi, maka akan muncul tampilan speperti Gambar 3.

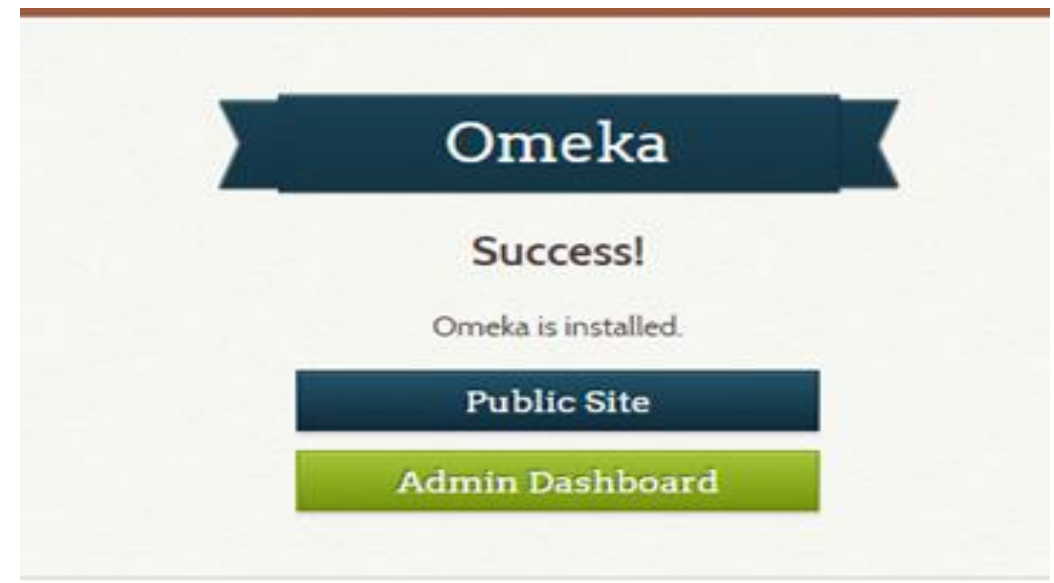

Gambar 3. Tahap Akhir Instalasi Omeka

Selesai instalasi, dipilih theme Seasons dengan style sheet Autumn, dan dilanjutkan dengan merancang/desain logo untuk masukkan pada isian theme. yang dipilih adalah Seasons. Perancangan logo dilakukan dengan menggunakan aplikasi Logo Maker yang berbasis Android. Rancangan logo dapat dilihat pada Gambar 4.

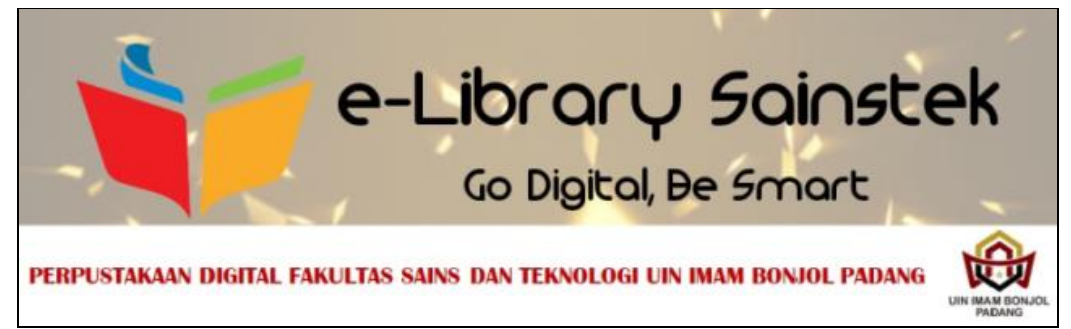

Gambar 4. Logo dan Nama Perpustakaan Digital

Setelah itu, pada isian Logo File di menu Configure Theme : Seasons, dipilih file logo tersebut, dan diketikkan pada HomepageText ucapan : Selamat Datang di Perpustakaan Digital Fakultas Sain dan Teknologi UIN Imam Bonjol Padang. Lalu dilakukan refresh alamat url : localhost/omeka, sehingga tampak tampilan Home / Beranda seperti pada Gambar 5 berikut ini.

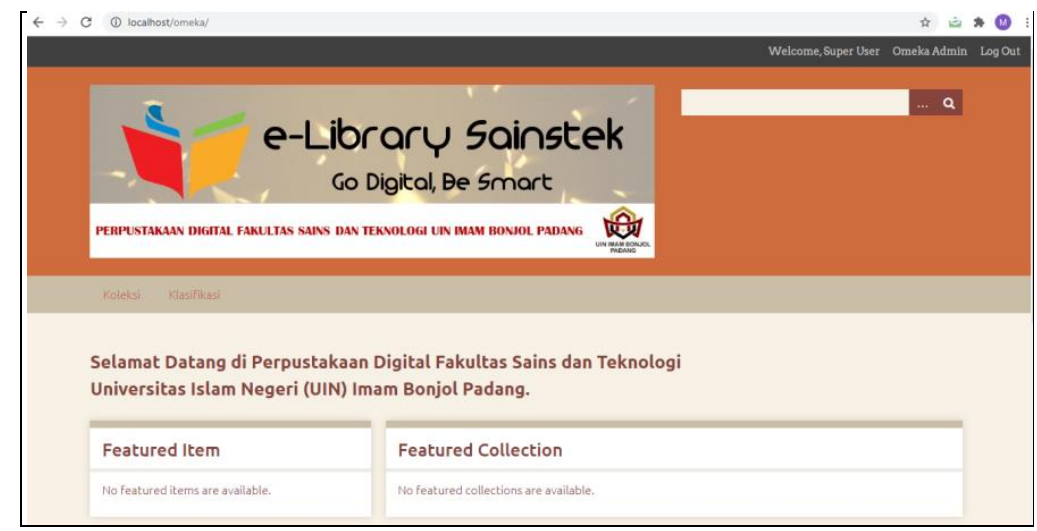

Gambar 5. Tampilan Beranda Perpustakaan Digital 
Langkah selanjutnya dari pembuatan rancangan perperpustakaan digital ini adalah mengisi menu Collection. Menu ini adalah tempat membuat klasifikasi koleksi yang ada di perpustakaan, bukan tempat mengunggah koleksi. Hasil pengisian menu ini akan menjadi Tab Klasifikasi. Sedangkan tempat menggunggah koleksi adalah di menu Item, yang kemudian akan tampil menjadi Tab Koleksi. Hasil pengisian Tab Koleksi dapat dilihat pada Gambar 6 di bawah ini.

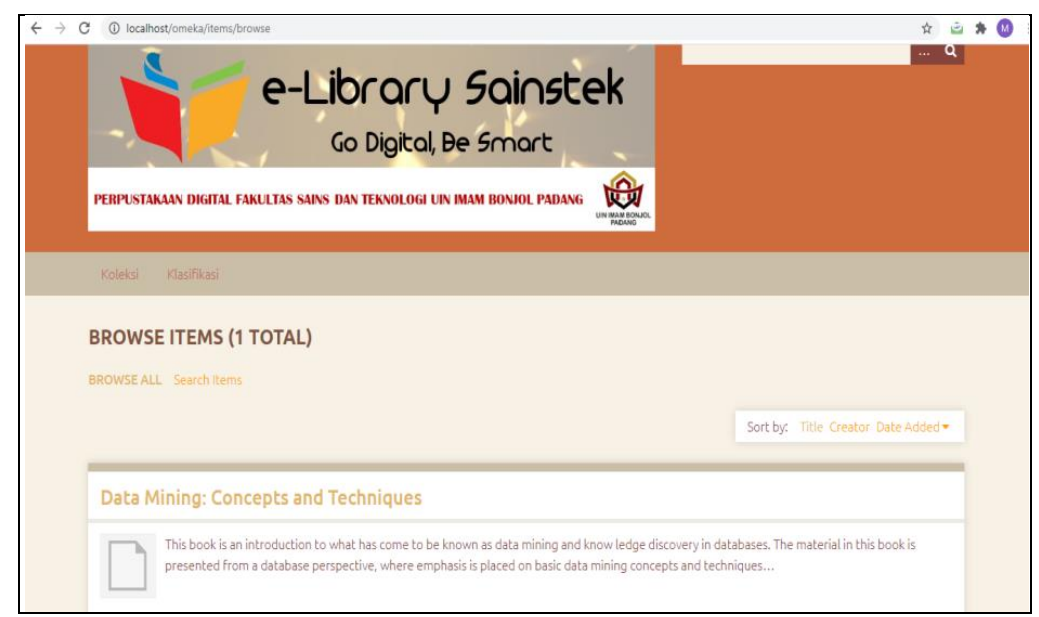

Gambar 6. Tampilan pada Tab Koleksi

Sedangkan hasil pengisian tab Klasifikasi dapat dilihat pada Gambar 7.

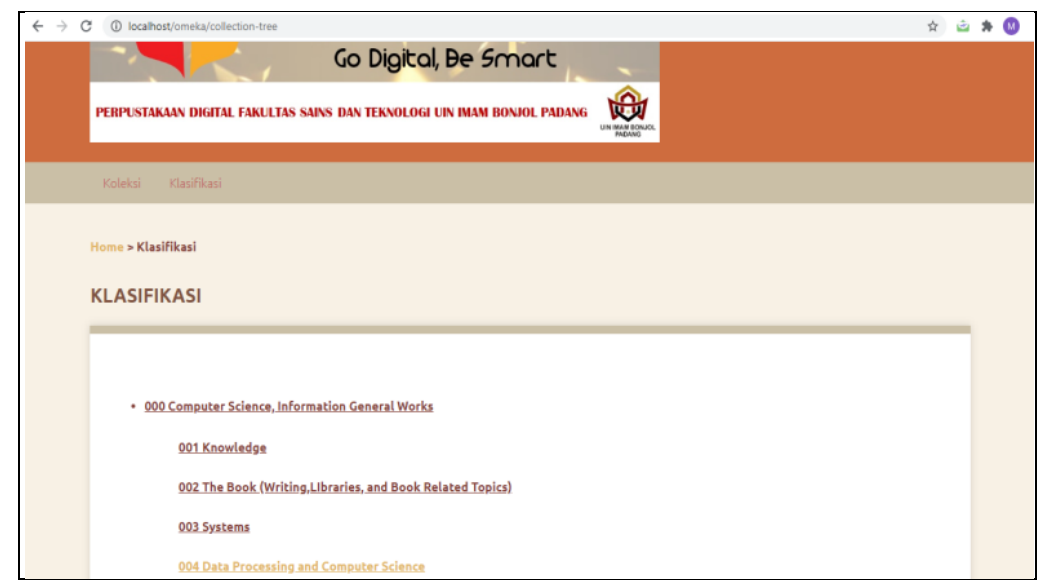

Gambar 7. Tampilan Tab Klasifikasi

Jika dipilih koleksi item Data Mining : Concept and Techniques, atau dipliih klasifikasi 004 Data Processing and Computer Sciences, maka kan muncul Tampilan Koleksi Buku Data Mining seperti Gambar 8. 


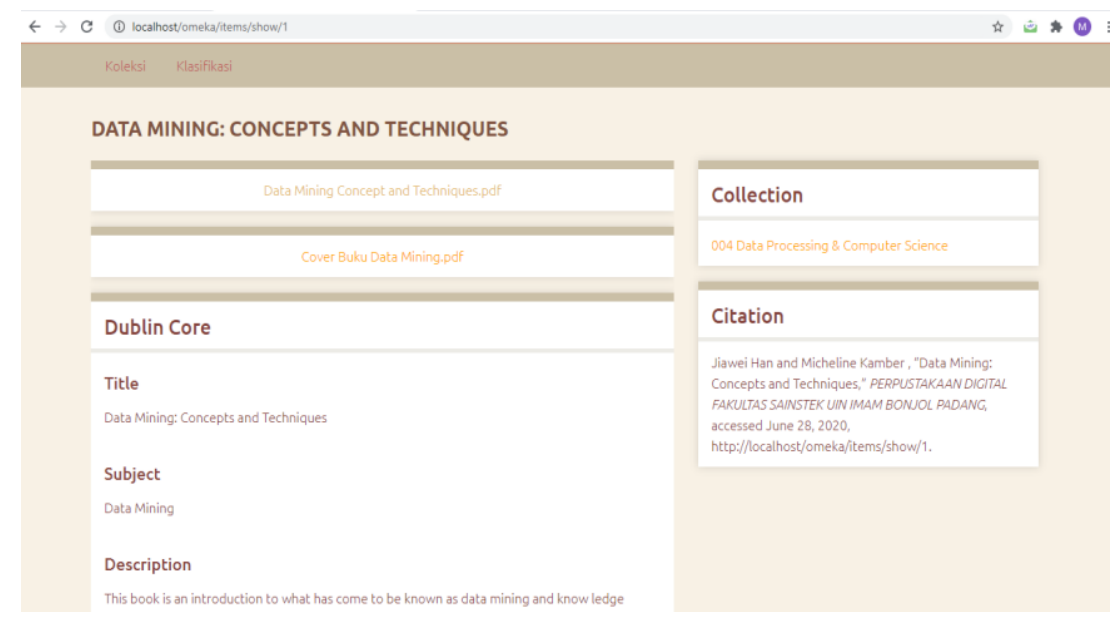

Gambar 8. Tampilan Koleksi Buku Data Mining

Jika dipilih Data Mining Concept and Techniques.pdf, maka akan tampil file pdf buku Data Mining tersebut. Sedangkan jika dipilih file Cover Buku Data Mining.pdf, maka akan tampil cover buku tersebut. Demikian seterusnya untuk koleksi-koleksi yang lain.

Rancangan ini masih berupa prototype yang diujicobakan kepada dosen dan mahasiswa UIN Imam Bonjol Padang. Hasil angket menunjukkan bahwa 85\% menyatakan bahwa rancangan ini bagus dan layak digunakan, dengan catatan harus dilengkapi lagi dengan koleksi-koleksi lain yang dibutuhkan oleh dosen dan mahasiswa, sekaligus dapat segera di-hosting.

\section{KESIMPULAN}

1. Berdasarkan pembahasan di atas, dapat disimpulkan bahwa tujuan penelitian ini sudah tercapai dengan terbentuknya rancangan perpustakaan digital Fakultas Sains dan Teknologi UIN Imam Bonjol Padang. Rancangan ini dibangun dengan menggunakan Omeka, dan telah disarankan oleh para calon pengguna (sivitas akademika) untuk segera dilengkapi koleksi-koleksinya dan ditambahkan fitur-fitur pelengkap yang dibutuhkan, sebelum dilakukan hosting.

2. Dari hasil penelitian dan percobaan, selain kelebihan dalam kemudahan instalasi dan penggunaannya, juga terdapat beberapa kekurangan Omeka. Diantaranya adalah file koleksi yang dapat diunggah (upload) tidak boleh melebihi 2 MB per file. Selain itu, rancangan yang dilakukan di Omeka terbatas, harus sesuai dengan fasilitas theme yang dipilih. Hal ini tentunya sangat membatasi kebebasan dalam mengunggah file dan merancang perpustakaan digital.

\section{DAFTAR PUSTAKA}

Arnomo, Ilham.(2018). Perbandingan Perangkat Lunak Repository Institusi:Studi Kasus pada Repository Institusi di Indonesia, Inform:Jurnal Ilmiah Bidang Teknologi Informasi dan Komunikasi Vol.3 No.1, Januari 2018 diambil dari http://download.garuda.ristekdikti.go.id/article.php?article=654079\&val=10419\&title=Perbanding an $\% 20$ Perangkat $\% 20$ Lunak\%20Repository\%20Institusi $\% 20 \% 20 \% 20$ Studi $\% 20$ Kasus $\% 20$ pada $\% 2$ 0Repository\%20Institusi\%20di\%20Indonesia. 
Faida, Ulfa Chusnul (2015). Institusional Repository Sebagai Basis Pengembangan Perpistakan Digital diambil dari https://ulfachusnul.wordpress.com/2015/05/27/institutional-repository-sebagai-basispengembangan-perpustakaan-digital/

Fauziah,Jihan. (2019).10 Aplikasi Perpustakaan Terbaik di Smartphone Android diambil dari https://carisinyal.com/aplikasi-perpustakaan/

Hakim, Heri Abi Burachman. (2015). Omeka : Aplikasi Pengelola Arsip Digital dalam Berbagai Format. Jurnal Jupiter Vol XIV No. 2 tahun 2015.

Hendrayanto,Johan dkk. (2010). Perancangan Arsitektur Perpustakaan Digital UPH dan Relevansi Dspace Sebagai Solusi Pengelolaan dan Penyebaran Grey Literature. Jurnal Pustakawan $\begin{array}{llllll}\text { Indonesia, Vol } & 10, & \text { No } & 2 & \text { Tahun } & 2010\end{array}$ dari http://journal.ipb.ac.id/index.php/jpi/article/viewFile/5275/3690

Nasution, Muhammad Syafii dan Samosir, Fransiska Timori.. (2016). Studi Komparasi Aplikasi Institutional Repository Dspace, Eprints, dan Omeka Dalam Rangka Pengembangan Aset Digital di Perguruan Tinggi http://www.pdii.lipi.go.id/read/data/2016/08/Sis4_Syafii_2016.pdf

Nurrika,Aswita. (2012). Modul LMS Sef hosted Omeka. PTIK Univeristas Negeri Semarang.2012 diambil dari https://dokumen.tips/documents/5302412024-modul-omeka.html

Purwoko. (2015). Omeka : Open Source Web Publishing, 2015 diambil dari http://www.purwo.co/2015/04/omeka-open-source-web-publishing.html

Saputra, D.F. (2015). Repositori Institusi Berbasis Omeka (Studi Kasus di Medical Knowledge Centre FK UPN VJ). Jurnal Ilmu Perpustakaan, Informasi, dan Kearsipan Khizanah Al Hikmah, vol 3 no Januari - Juni 2015, hal 11-19, diambil dari http://journal.uin-alauddin.ac.id/indeks.php/khizanahal-hikmah/article/view/585

Website resmi Omeka www.omeka.org

Wikipedia. PerpustakaanDigital, 2020 diambil dari https://id.wikipedia.org/wiki/ Perpustakaan_digital 